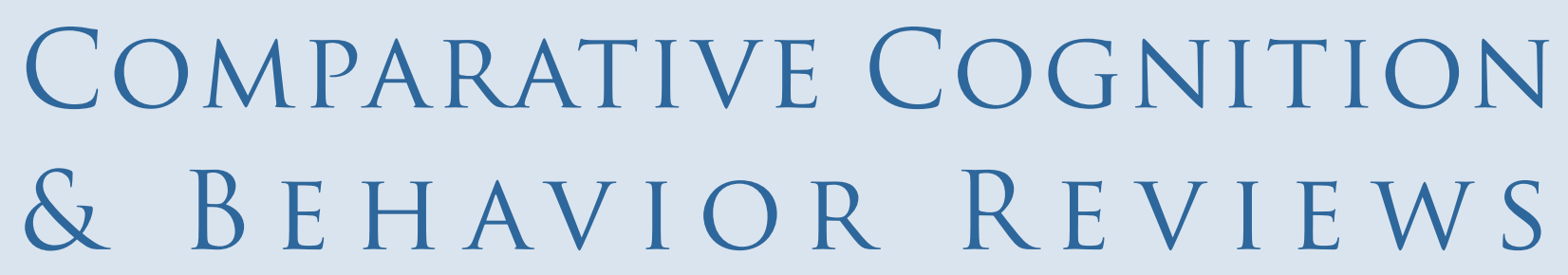

\title{
What Can We Learn About Navigation From Associative Learning?
}

\author{
Anthony McGregor \\ Durham University
}

The many cue types that animals are able to use for both long- and short-scale navigation have been studied extensively, and a well-researched literature has developed into the strategies that have evolved to exploit information provided by these different cues. Less well understood are questions of how animals select different cues to learn about, and the conditions for learning based on these cues. These queries have tended to concern psychologists interested in the extent to which the principles of associative learning apply to spatial learning. The question is of interest because the predictions of associative learning theories are often at odds with spatial learning theories, which instead tend to emphasize the special types of representation and learning process necessary for navigation. Here I examine spatial learning from an associative perspective, starting with the question of what kinds of associations are formed in associative learning and how these may fit within our knowledge of spatial learning. I then examine the conditions of learning, including the effects of prior experience on spatial learning in terms of both latent inhibition and perceptual learning, changes to the attention paid to spatial stimuli as a result of their predictive history, and the extent to which redundancy - when multiple cues predict same outcome-affects learning. The effects are illustrated mostly with examples from the associative learning literature, which is often with rodents or pigeons. But where possible, I have demonstrated similar effects in more diverse species and have tried to indicate the general learning effects that associative learning theories predict.

Keywords: spatial learning, associative learning, cue competition, cognitive map, geometry

\section{Introduction}

The histories of the study of associative learning and spatial learning are intrinsically linked. The purpose of this article is to review the contents and conditions of spatial learning from an associative learning perspective. The rat's natural proclivity for short-scale navigation and the ease with which it could be housed in the laboratory made it an ideal experimental subject in the early 20th century. The objective of much of this early comparative work was to determine what was actually learned during learning, and spatial problem solving seemed an ideal paradigm for answering such a question. Observations of the rat's navigation to a rewarded location through interconnected alleys led early researchers to the conclusion that learning was the result of trial and error (e.g., Small, 1901). In particular, the author of the behaviorist manifesto, John B. Watson, concluded 
from the results of various navigation experiments that such trial-and-error learning was driven by kinaesthesia, with little input from sensing the external environment (Carr \& Watson, 1908; Watson, 1907). Such conclusions drove stimulus-response (S-R) theory as a fait accompli for explaining learned behavior.

Later observations, most famously from Tolman's laboratory, showed that rats did learn to navigate to a goal using external cues, which Watson (1907) had also observed but had downplayed. For example, Tolman, Ritchie, and Kalish (1946) trained rats in a T-maze to move to where food was located at one of the two goal arms, always starting the trial at a fixed point in the start arm. At the end of training, rats received a probe in which the entire maze was rotated $180^{\circ}$ so that they started from the opposite location to the start position during training. The rats could either follow the response made during training (e.g., turn right at the choice point) or go to the location in the room where the food was placed during training (e.g., the west side of the room). These "response" and "place" strategies would lead the rats to opposite locations in the T-maze. The results showed that rats were capable of learning both strategies. Although proponents of S-R theory argued that the use of such external cues was not inconsistent with S-R theory, albeit with a reduced emphasis on kinaesthesia (e.g., Restle, 1957), it has been suggested that S-R theory fails to acknowledge the flexibility (e.g., Blodgett, 1929; Tolman \& Honzik, 1930) and apparent ease (e.g., Tolman et al., 1946) with which learning based on such environmental cues takes place, which seemed to indicate that animals had an expectation of the outcomes of their behavior-something that S-R theory did not include. This behaviorist/cognitivist distinction led to two dual-process accounts of learning - one that continued to explore spatial learning and led, most famously, to cognitive map theories (e.g., O'Keefe \& Nadel, 1978; Tolman, 1948), and a second that removed the animal from the maze and placed it into an automated conditioning chamber to investigate instrumental conditioning

Author Note: Anthony McGregor, Department of Psychology, Durham University, South Road, Durham, DH1 3LE, United Kingdom.

Correspondence concerning this article should be addressed to AnthonyMcGregor at anthony.mcgregor@durham.ac.uk.

Acknowledgments: This work was supported by grants from the BBSRC and ESRC. Thanks to David Sanderson for helpful comments on this manuscript. (e.g., Balleine \& Dickinson, 1998). The former account has tended to emphasize shortcomings in associative learning theory in explaining flexible spatial learning, whereas the latter account has developed and enhanced our understanding of associative learning.

Part of the reason for the development of spatial learning theories that do not include the role of associative processes may be due to the erroneous conflation of associative learning theory with behaviorism (Rescorla, 1988). Another part may be due to psychological accounts of spatial learning that have arisen from the observation of the behavioral correlates of single neurons in the rodent brain (review in Poulter, Hartley, \& Lever, 2019). The purpose of this article is to review the contents and conditions of spatial learning from an associative learning perspective. I first analyze what is learned in spatial learning and how it relates to modern analyses of associative learning, with particular reference to the similarities between the different dual-process theories just mentioned. In this case, I review the associative structures that could be at play. I try to determine whether complex representations of space can be accounted for by these associative structures, or whether it is necessary to invoke the notion of a cognitive map, as much of the neuroscientific and behavioral literature suggests. It may be that associative structures fall short of being able to explain the most complex spatial behaviors in animals. I then assess the conditions under which spatial learning progresses. Here, cognitive map theory often makes quite different predictions to associative learning theory, but I argue that these accounts have tended to overlook phenomena that are predicted only by associative theories. For example, studies of how exposure to stimuli affects subsequent learning, or how redundancy of spatial information affects learning, strongly indicate a role for associative processes and are not accounted for in purely spatial accounts. The challenges for researchers of spatial learning in incorporating evidence both for and against the role of associative learning in navigation are set out at the end of the article.

\section{Cognitive Maps and $S-R$ Learning}

O'Keefe and Nadel (1978) surveyed behavioral, lesion, and electrophysiological evidence and concluded that there were two navigational mechanisms. One mechanism was based on the S-R approach just outlined, together with a guidance strategy based on responding to patterns of simulation in the environment, such as approaching or avoiding particular objects. In

COMPARATIVE COGNITION \& BEHAVIOR REVIEWS 
these cases, learning reflected the action of associative processes, which they termed taxon learning. An important aspect of the characterization of taxon learning was that it depended on reinforcement (O'Keefe \& Nadel, 1978, p. 100). In addition, the taxon system was not necessarily dependent on a metric representation of space, in that taxon strategies do not require an appreciation of the distances and directions between cues in the environment to navigate effectively. A number of navigational strategies may be thought of as belonging to this category, including the response learning just mentioned - which may be described as a routefollowing strategy - and others, such as view-matching strategies in insects (e.g., M. Collett, Chittka, \& Collett, 2013) and birds (e.g., Pritchard \& Healy, 2017), and beaconing using visual landmarks (insects: Cheng, 2012; pigeons: Cheng, Spetch, Kelly, \& Bingman, 2006).

The second system, O'Keefe and Nadel argued, was based on an isomorphic representation of allocentric space in the brain, which they termed locale learning. This locale learning was the basis for a cognitive map, which allowed the animal to learn about places in the environment, their relation to other external cues, and the position of the animal itself. It could be said that such a map would provide the animal with a global representation of its familiar environment (Gallistel, 1990; Poucet, 1993). This cognitive mapping was, they claimed, computationally efficient, domain specific, flexible, and robust, and was formed by exploration of the environment without the requirement for reinforcement, in contrast to the conditions for taxon learning. In short, it was not the result of associative processes. The behavioral evidence for such a cognitive map came from studies demonstrating the inadequacy of S-R theory for explaining spatial behavior, such as the place and response learning dissociation by Tolman et al. (1946). However, the characterization of associative learning as simply an S-R connection, wholly dependent on the co-occurrence of a reinforcer, does not reflect the richness of research into its characteristics or properties. Indeed, O'Keefe and Nadel's dualprocess account of spatial behavior was published at a time when other exciting developments in our understanding of instrumental conditioning were being revealed. These theories of instrumental conditioning showed that associations between events included more than merely the connection between a stimulus representation and a response, and they largely confirmed the positions put forward as part of Tolman's purposive behaviorism approach. As such, it is important to consider what they may tell us about the nature of spatial learning.

\section{Is Spatial Learning Goal-Directed?}

One of the key aims of Tolman's program of work was to determine whether animals acted purposively. That is, do they have an expectation of the outcomes of their behavior? To that end, Tolman's maze experiments were designed to test if an animal could navigate to a location regardless of the route it had taken to get there, as we have already seen. We may refer to this kind of association as $\mathrm{R}-\mathrm{O}$, in that it requires the association of an action (response) with the outcome. S-R learning has no capacity for such an association. For Tolman, the importance of learning was that it was goaldirected. Although the behavior of animals in Tolman's and others' experiments (e.g., Elliot, 1929; Tinklepaugh, 1928) seemed to indicate goal-directedness, S-R theorists such as Hull (1943) were able to point to other factors, such as Pavlovian associations, that could account for the observed effects. Even spontaneous spatial alternation has been argued to be the result of simple nonassociative habituation mechanisms rather than the result of goal-directed action. Sanderson and Bannerman's (2012) demonstration that deletion of the GluA1 subunit of the AMPA receptor impaired such spatial alternation, as well as short term but not long term habituation, led them to interpret alternation in terms of simple nonassociative processes. Only the development of inspired behavioral tests in the nonspatial context of instrumental conditioning studies finally demonstrated goal-directed instrumental action (for reviews, see Dickinson, 1985; Dickinson \& Balleine, 1994). One of these tests is postconditioning outcome devaluation (e.g., Adams \& Dickinson, 1981; Colwill \& Rescorla, 1986). Typically in outcome devaluation, the value of the reinforcer is reduced by pairing it with an aversive event, such as illness, in the animal's home cage, where there is no opportunity to make the instrumental response. The animal's tendency to perform the instrumental response that had previously produced the nowdevalued outcome is then tested. Crucially, this test takes place in extinction, which prevents the animal from experiencing the devalued outcome as a result of the instrumental response. Therefore, the devalued reinforcer has no opportunity to modify the strength of the S-R association directly, so we may conclude that any change in its behavior must be because of the animal's expectation about the value of the reinforcer. Thus, in this procedure it is not an animal's spatial behavior that tells us about whether it expected the outcome but the sensitivity of a given response (R) to the expected value of the outcome $(\mathrm{O})$ - that is, its goal-directedness. 
The question of interest is whether this associative analysis of goal-directedness can be extended to studies of spatial learning. Surprisingly few studies have examined this question using the successful methodology adopted to provide support for the dual-process (S-R and R-O) account of instrumental conditioning. S-R associations are said to form as a result of learning the instrumental contingencies between a response and a reinforcer, whereas $\mathrm{R}-\mathrm{O}$ associations represent the causal relationship between an action and its consequences (Balleine \& Dickinson, 1998). The limitations of a purely S-R account of learning are made clear when one considers that S-R learning precludes an animal from "knowing" about the consequences of its actions, which would prevent it from being able to decide between different actions based on its current motivational requirements. Recently, experiments from our own laboratory used the classic T-maze apparatus used by Tolman et al. (1946) to dissociate response and place spatial strategies. We applied the outcome devaluation procedure to them to determine if they correspond to the dual-process account of instrumental conditioning just discussed (Kosaki, Pearce, \& McGregor, 2018). In the first experiment, rats were trained to discriminate arms in the T-maze by finding a distinctively flavored food in one (see Figure 1). In their home cages, the rats were then fed either the food reward or their maintenance diet to satiety. Thus, level of hunger was equated between the two conditions, but the value of the reinforcer experienced as part of the task in the T-maze was altered in only one. In two extinction test trials, one with the outcome devalued and one with no devaluation, rats were released from the opposite location to that used during training. We could therefore dissociate place from response learning. Under nondevalued conditions, rats displayed no particular preference for the response or place strategy, but under outcome devaluation they switched to the response strategy by avoiding the goal location. One issue with this finding was that rats might simply have reacted to the devaluation of the outcome using only the place strategy and that they did not rely on the response strategy during any part

Figure 1. Schematic diagram of the design used by Kosaki et al. (2018). Rats were trained on a dual-solution task in a T-maze (left panel). Immediately preceding the test trial, rats were given free access to either reinforcer pellets in the devaluation condition, or maintenance diet in the no devaluation condition (middle panel). The test trial was conducted in extinction. The rat was released from a novel start arm opposite that used during training. Two test trials were conducted, following prefeeding of either the reinforcer pellets or the maintenance diet, in a counterbalanced order (right panel).

Training

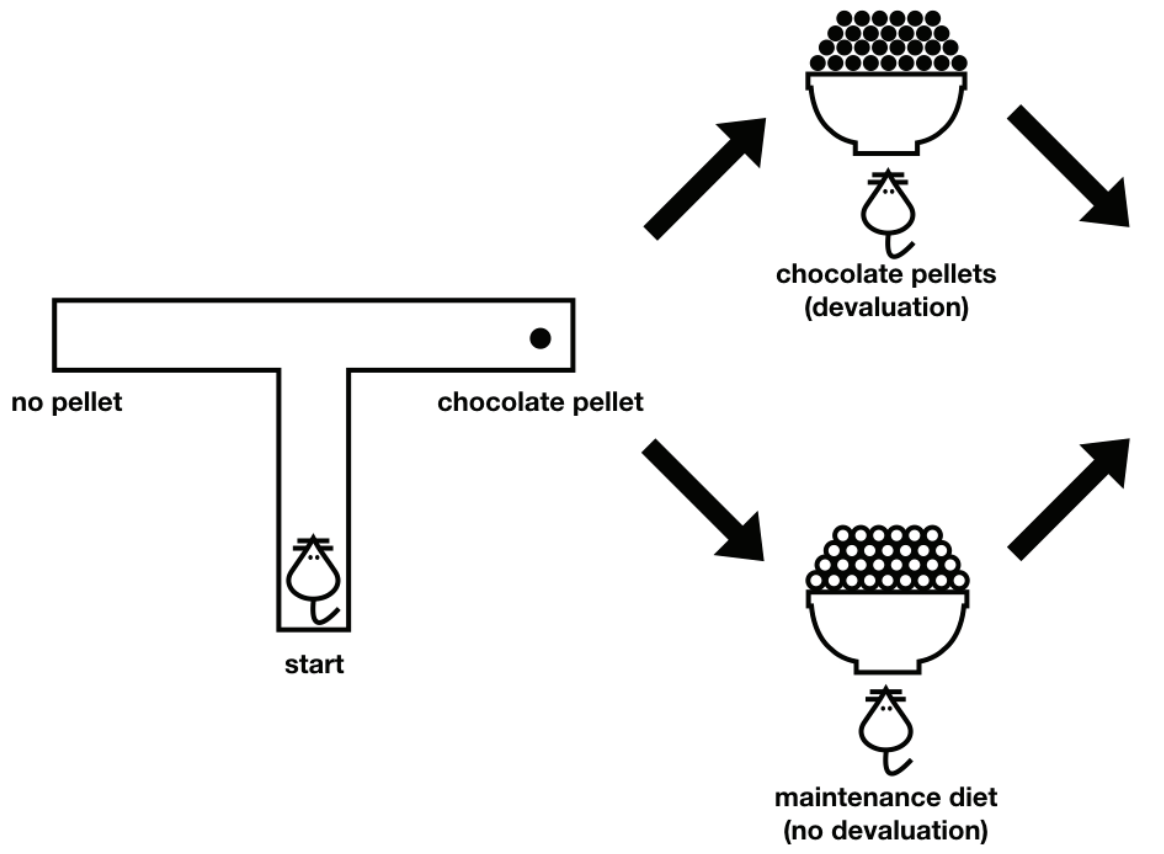

\section{Pre-feeding} (free access)

(no devaluation)
Test trials

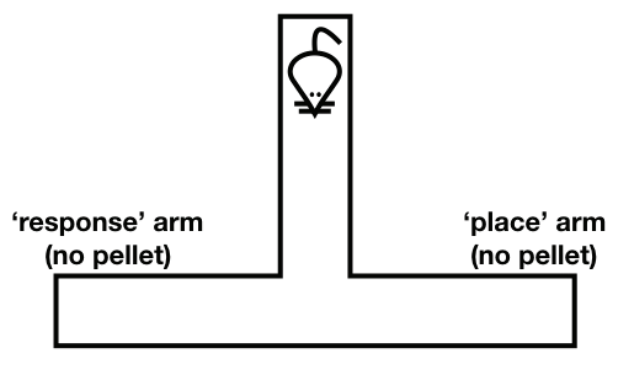

'response' arm (no pellet) 
of the probe trials. We could not conclude, therefore, that the response strategy was not sensitive to outcome devaluation. Therefore, in Experiment 2 we removed the opportunity to learn the place strategy by lesioning the hippocampus, which impairs place learning but not response learning (Packard \& McGaugh, 1996). The external environmental cues were also enhanced to encourage the sham-operated controls to rely more on the place strategy. As expected, the shams showed place learning and the hippocampal group showed response learning. Although both groups in both conditions continued to follow the fixed response they learned during training, the outcome devaluation altered the sham group's behavior by slowing their movement to the goal location but did not affect the hippocampal group's behavior. The results are consistent with a correspondence between the spatial literature dichotomy of place and response learning, and the instrumental conditioning literature of action (R-O) and habit (S-R); results show that in spatial learning, associative structures are not limited to S-R habits, as was assumed in O'Keefe and Nadel's dual-process account. For similar results, albeit with slightly different procedures and controls, see also De Leonibus et al. (2011; mice), Sage and Knowlton (2000; rats), and Yin and Knowlton (2002, 2004; rats).

\section{Latent Learning}

An early argument about the nature of spatial learning was that it was not necessarily driven by reinforcement, in contrast to the prevailing view of the development of S-R associations. A literature quickly developed showing that spatial learning could occur in the absence of any obvious reinforcement. For example, Blodgett (1929) allowed three groups of rats to explore a maze of interconnected T-mazes, always placing the animals into the same part of the maze. For one group, a goal box contained food from the outset of the experiment, and these animals learned quickly to run directly to the food, making few errors to reach it. The other two groups were not reinforced in this way, and they made many errors before they reached the same box that contained food for the first group. However, once food was introduced, at a different time point for each group, these animals ran almost immediately without error to the goal box. Such latent learning might be described as incidental and could certainly not be claimed to be the result of S-R learning. A central component of O'Keefe and Nadel's (1978) theory was that cognitive maps were formed by exploration and that novelty, rather than reinforcement, was a key factor in spatial learning. The implication is that such mapping behavior cannot be explained by associative processes. However, we have already seen that $\mathrm{S}-\mathrm{R}$ theory is an incomplete account of associative learning, and maze-running experiments such as Blodgett's helped to show this. Modern associative learning theory has long had to account for the formation of S-S associations in the absence of a reinforcer, exemplified by effects such as sensory preconditioning (e.g., Rescorla \& Cunningham, 1978; Rizley \& Rescorla, 1972). Indeed, such sensory preconditioning effects have been reported in spatial learning tasks with pigeons (Blaisdell \& Cook, 2005; Sawa, Leising, \& Blaisdell, 2005), rats (Chamizo, Rodrigo, \& Mackintosh, 2006), and humans (Bouchekioua, Miller, Craddock, Blaisdell, \& Molet, 2013; Molet, Jozefowiez, \& Miller, 2010; Prados, Alvarez, \& Reynolds, 2011). For example, Chamizo, Rodrigo, and Mackintosh (2006) trained rats to find a platform in a swimming pool using two sets of distal landmarks, experiencing each on different occasions. For the experimental group, one of the landmarks in each set was common to both sets of landmarks. When tested with a new configuration of landmarks, excluding the common landmark, this group searched for the platform more accurately than a control group that had been trained without the common landmark. The results suggest that the rats integrated spatial information from different occasions without explicit reinforcement for doing so. These findings suggest that animals may be able to build up complex representations of space based on integrating simpler ones, in a manner consistent with the establishment of an associative chain. Of interest, a similar idea was hypothesized by Deutsch in 1960, who accounted for latent learning effects by theorizing that even without a goal present, animals could learn associations between stimuli close to one another in the maze. Once a reinforcer is introduced, a goal representation is established, and in turn that activates the representations of stimuli connected to it. Because learning is expected to occur without explicit reinforcement in associative learning theory, its observation in spatial contexts can hardly be used as evidence of nonassociative processes.

\section{S-S Learning}

The R-O association, discussed in the section on the goal-directedness of spatial learning above, may be seen as a specific form of S-S association in that it represents the association of one stimulus with another rather than 
simply with a response. Is there evidence more widely of the formation of these S-S associations in spatial learning? The existence of these kinds associations is crucial if we are to conclude that the flexible spatial behavior presented as evidence of locale learning by O'Keefe and Nadel (1978) is plausibly associative. It has been assumed by a number of "classic" early studies that spatial learning involves the representation of the goal. For example, Morris (1981) argued that the ability of rats to swim to a submerged platform in a swimming pool reflected the formation of a representation of the location of the platform with reference to landmarks outside the pool. The finding that rats seemingly swam directly to the platform location from a novel release point in the pool led Morris to conclude that navigation in the pool could not have been due to the formation of S-R associations. However, others have pointed out that it was impossible for Morris to prevent rats from encountering particular routes to the platform during training (e.g., Sutherland, Chew, Baker, \& Linggard, 1987). To overcome this criticism, Horne, Gilroy, Cuell, and Pearce (2012) prevented rats from developing $\mathrm{S}-\mathrm{R}$ associations by placing them directly onto a platform in one corner of a rectangular swimming pool. Regardless of the delay between training and test, or the number of occasions on which they were placed onto the platform, the rats showed a significant tendency to swim in the corners of the pool that were consistent with where the platform had been located during training, such as where a long wall was to the left of a short wall. One possibility was that this performance was the result of the formation of a cognitive map - a global representation of the environment (see also Cheng \& Spetch, 1998; Gallistel, 1990). However, in a final experiment, Horne et al. placed rats onto a platform in one corner of a rectangle during training before rearranging the walls to create a kite shape. The kite differed in its global shape from the rectangle but still shared local geometric features with the

Figure 2. Schematic diagram of training (left panel) and test (right panel) conditions in the study by Collett et al. (1986). The black circles indicate a landmark, and $\mathbf{s}$ indicates either the location of the seed (left panel) or search location (right panel).

Training

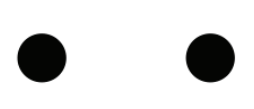

s

\section{Single landmark test}

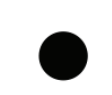

$\mathbf{s}$ rectangle-for example, a corner with a long side to the left of a short side was present in both shapes. Rats in this experiment still searched preferentially in the correct corner despite the change in overall shape. Horne et al. argued that such a result could only be the result of the formation of an S-S association during training and could not be due to S-R learning. They also argued that their results could not be explained by the development of a cognitive map during exposure to the arena, because the arena shapes during exposure and during test were different (see also Pearce, Good, Jones, \& McGregor, 2004, and the Relations Among Cues section). An important implication of this analysis is that associative learning does not have to be driven by reinforcement. A similar conclusion may be drawn from a rather different example - that of exploratory flights and walks in insects (T. S. Collett \& Zeil, 2018).

\section{Relations Among Cues}

So far, this associative analysis has been limited to discussing how animals navigate to a goal location. Can the existence of S-S associations also be used to explain how animals learn the relationship between one cue and another, such as the position of one landmark in relation to another? For this to be achieved, there must be some kind of spatial or geometric representation of the relations among stimuli in the environment, and any associative account of spatial representation must be extended to include the capacity for metric relations to be represented. T. S. Collett, Cartwright, and Smith (1986) demonstrated gerbils' ability to use the relationship between one landmark and another when navigating to find a hidden sunflower seed. The seed was placed among black granite chippings so that it could not be detected until the animal was very close, and it always maintained the same relationship to the two landmarks, which were visually identical. The seed was placed southeast of one of the landmarks and southwest of the other so that the three items formed the vertices of a notional isosceles triangle. The entire array was translated around the experimental room, and the gerbil's start position was altered from one trial to the next so that there was no fixed route to the food. However, the array was not rotated between trials, so direction was determined, presumably, by cues present in the room. Test trials at the end of training with one of the two landmarks removed showed the animals searching equally to the southeast and southwest of the remaining landmark (see Figure 2). This pattern of results was interpreted as the result of

COMPARATIVE COGNITION \& BEHAVIOR REVIEWS 
the gerbils having learned a vector from each landmark to the food, but without being able to determine which landmark was present, they searched at the ends of both vectors. One important inference of this finding is that when both landmarks were present, the position of one was able to provide some additional information that allowed the gerbil to calculate the directional component of the vector from the other landmark.

Other studies have drawn similar conclusions - that vectors constitute a vital element of spatial behavior, allowing animals to learn the relations among stimuli (e.g., Cheng, 1989, 1995, 2006; Gould-Beierle \& Kamil, 1996; Kamil \& Jones, 2000; McGregor, Good, \& Pearce, 2004; Spetch, Cheng, \& MacDonald, 1996). Such vector learning, using one landmark to determine the direction of a goal location from another, follows the same principle of the S-S learning just outlined - that one stimulus is associated with another to control behavior-but crucially, the nature of the representation is undeniably spatial in that it represents metric information about distances and directions among and between stimuli. It may be that this vector learning, based on spatial relations among multiple landmarks, might allow the expression of complex spatial behavior (Biegler, McGregor, \& Healy, 1999; Kamil \& Cheng, 2001). However, Mackintosh (2002) argued that this does not necessarily constitute evidence for a cognitive map, as defined as a global representation of spatial relations in a familiar environment (Gallistel, 1990; Poucet, 1993).

One way of determining if such a global representation exists is to transform the global array of stimuli in the environment to establish if spatial search breaks down. Geometry learning is an example of spatial learning that some have claimed relies on a global representation of space. The importance of environmental geometry for determining direction (Cheng, 1986) and location (Doeller \& Burgess, 2008) has been demonstrated in a wide variety of taxa (review in Cheng \& Newcombe, 2005). Cheng's (1986) seminal work involved training rats to find food in one corner of a rectangle - say, with the long side to the right of the short side-before removing them and rotating the arena. When returned to the rectangle, the rats tended to search in the same corner, and the diametrically opposite one, evidently using the geometric cues to reorient themselves because the configuration of wall lengths was the same in these corners (e.g., corners A and C in Figure 3). The rats did this despite the presence of distinct visual/odor cues in each corner that could have disambiguated them. Cheng and Spetch (1998) specifically defined animals' use of geometry as a configural representation of the broad shape of the environment, which did not involve the use of the elemental stimuli that made up the shape. Therefore, the representation of environmental geometry is a candidate for determining if animals encode the global layout of the environment. Arguably, an alternative interpretation for such results would be that the rats learned the local geometric relations of walls in different corners but did not necessarily stitch these together into a global representation. To test this possibility, Pearce et al. (2004) trained rats to locate a platform in a rectangular swimming pool much like that used by Horne et al. (2012) described earlier, with the exception that rats were released into the pool to

Figure 3. The arenas used by Pearce et al. (2004) during training (left panel) and test (right panel). Corners A and C in the rectangle are geometrically equivalent to corner $\mathbf{E}$ in the kite. The principal axis is indicated in each shape as a dotted line.

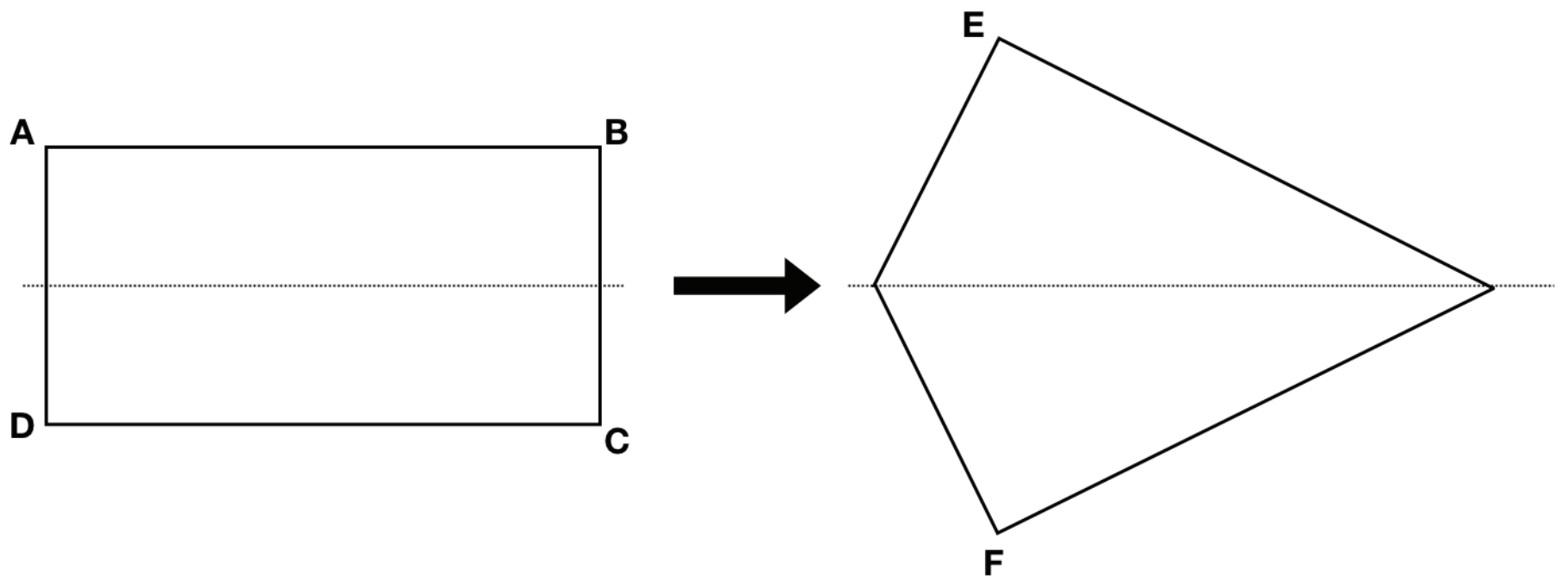


swim to the platform. At the end of training, the entire shape of the pool was transformed to that of a kite (see Figure 3), which contained the same elements and maintained some of the local geometric relations among the long and short walls (e.g., corners A and C) but which, crucially, was a different overall shape than the training environment. Despite this change in shape, the rats continued to discriminate the correct (e.g., E) from the incorrect right-angled corner (e.g., F). Although the use of a maplike representation seemed to be ruled out by these results, Cheng and Gallistel (2005) pointed out that the locations of the correct right-angle corners in both the rectangle and the kite could be defined with respect to other global shape parameters, such as the principal axis or medial axes of the shapes. In the case of the rectangle and kite shown in Figure 3, the dashed line on each shape shows the principal axis.

The hypothesis that rats might be using the principal axis to generalize across environments was tested by McGregor, Jones, Good, and Pearce (2006). The authors trained rats to swim to a platform in an irregular pentagon as shown in Figure 4. The platform was always located in the same right-angled corner (corner S or R, depending on counterbalancing) during this training. If rats were using the principal axis, shown as a dashed line, to locate the correct corner, then when tested in a transformed rectangular arena, the rats should transfer their search accordingly. Specifically, a rat trained to find the platform in corner $\mathrm{S}$ of the pentagon should search in corners $\mathrm{V}$ and $\mathrm{X}$ of the rectangle. This prediction is the direct opposite of the local geometry account, which supposes that rats would search in corners $\mathrm{W}$ and $\mathrm{Y}$. The results supported the local geometry account. However, it is possible that animals are capable of forming both global and local representations of the shape of the environment and that altering the overall shape forces the animal to employ only the local representation. Kelly, Chiandetti, and Vallortigara (2011) found some support for the medial axes account of Cheng and Gallistel (2005) using pigeons and chicks in another transformation experiment. They trained their birds to find food in one corner of a rectangle before testing in a L-shaped arena (see Figure 5). The local geometry account would predict that animals trained in corner $\mathrm{A}$ of the rectangle would search in corners $\mathrm{K}$ and $\mathrm{N}$ in the L-shape, which is what both pigeons and chicks did. However, they also searched in corner $\mathrm{O}$, which would be predicted by the medial axis account. Pigeons searched there more than chicks, which led the authors to the conclusion that pigeons relied primarily on medial axes, whereas chicks primarily used local geometry followed by medial axes. There is also evidence that humans are able to use the principal axis (Ambosta, Reichert, \& Kelly, 2013; Bodily, Eastman, \& Sturz, 2011) and that they have both local and global representations available to them (Buckley, Smith, \& Haselgrove, 2016; Lew et al., 2014). Of interest,

Figure 4. The arenas used by McGregor et al. (2006) during training and test. The principal axis of each shape is denoted with a dotted line. Corner $\mathbf{S}$ in the pentagon is geometrically equivalent to corners $\mathbf{Y}$ and $\mathbf{W}$ in the rectangle.

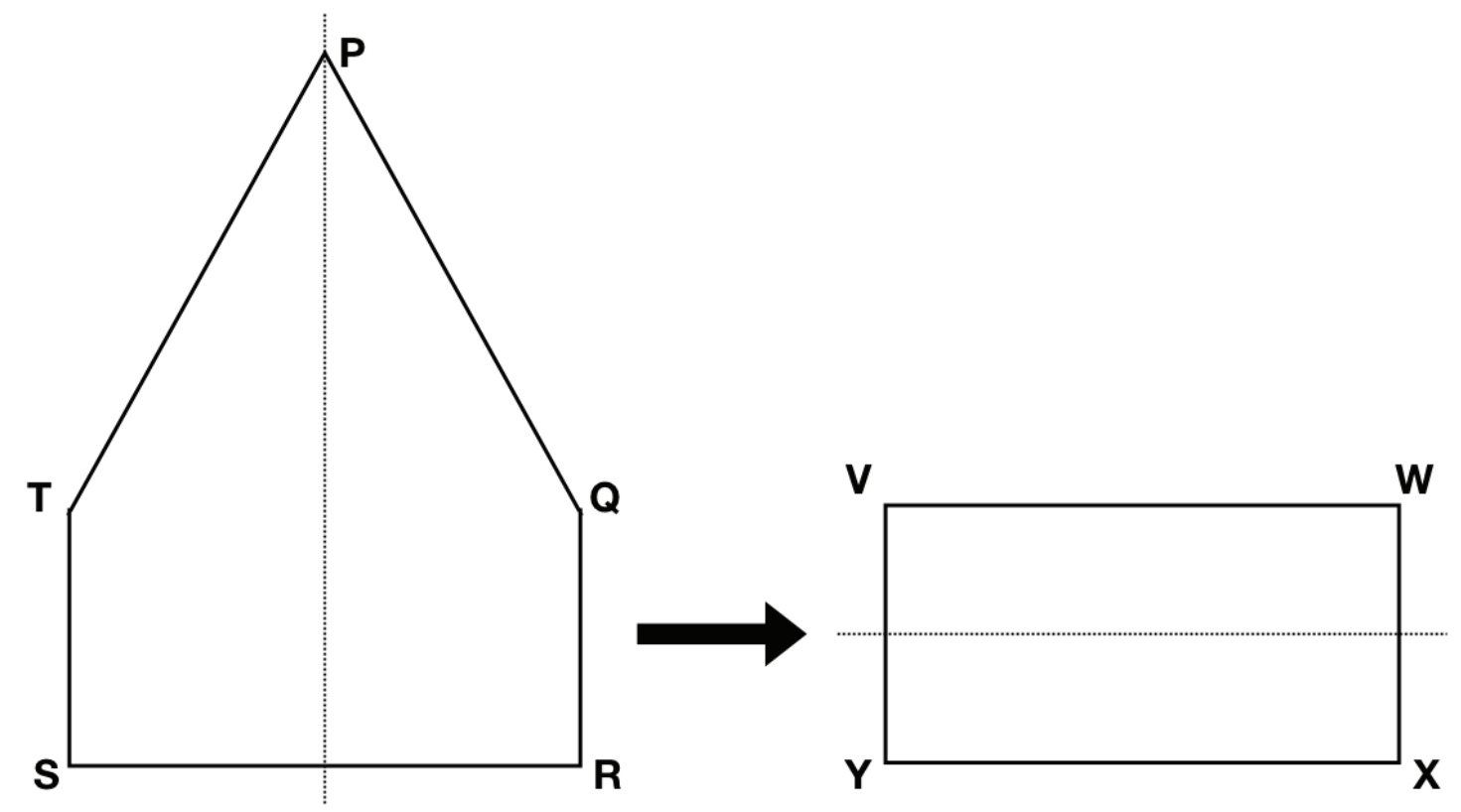

COMPARATIVE COGNITION \& BEHAVIOR REVIEWS 
however, recent research questions the evidence for both the local geometry account and the principal/medial axes accounts. Sotelo, Nardi, et al. (2019) with pigeons, and Sotelo, Alcalá, Bingman, and Muzio (2019) with a terrestrial toad, employed a similar transformation design as Pearce et al. (2004) and failed to find any evidence that either species was able to transfer their search from a rectangle to a kite. The results are difficult to explain without assuming that during training in the rectangle, the pigeons and toads had formed the kind of global geometric representation assumed by Cheng and Spetch (1998) to underlie Cheng's (1986) findings.

The possibility that (some) animals are able to form such global representations may be said to give support to the notion of a cognitive map. Definitions of cognitive maps vary (e.g., Gallistel, 1990; Leonard \& McNaughton, 1990; O'Keefe \& Nadel, 1978), and some have argued that the concept of a cognitive map is flawed for this very reason (e.g., Bennett, 1996). However, it is generally recognized that they should allow the animal to represent the interrelations among objects and surfaces in its environment and that the animal should be in some sense independent of the representation, so that its own position within the map can be represented. The original formulation of the hippocampus-based cognitive map by O'Keefe and Nadel (1978) supposed an isomorphic representation of environmental space in the hippocampus by place cells, which respond to a rat's position in space regardless of its route and the direction it is facing. Discoveries of other cells have followed, including head direction cells, which respond when the animal faces a particular direction but which are invariant to its position (e.g., Taube, Muller, \& Ranck, 1990), and grid cells in the entorhinal cortex (e.g., Hafting, Fyhn, Molden, Moser, \& Moser, 2005), which have been proposed to provide a metric input of distance and direction information to the place cells in the hippocampus. Not all neuroscientists agree that the existence of such cells compels us to accept the existence of a cognitive map, however (e.g., Leonard \& McNaughton, 1990), because nonmapping accounts of their function are viable. In addition, because the function of the different cells is under very active research, an agreed account of their function is not yet available. For example, although the preceding global representation account may fit best with the hypothesis put forward by O'Keefe and Nadel (1978), recent evidence from O'Keefe's laboratory fits better with the local geometry hypothesis put forward by Pearce et al. (2004; see Krupic, Bauza, Burton, \& O'Keefe, 2018). In addition, some of the most compelling evidence for the existence of a cognitive map comes from the invertebrate literature (e.g., Cheeseman et al., 2014), in animals that do not possess the rodent's neural architecture. Even this evidence, however, is open to criticism that design flaws preclude the conclusion that animals possess cognitive maps. For example, both

Figure 5. The arenas used by Kelly et al. (2011) during training (left panel) and test (right panel). The medial axes of each arena are shown as dotted lines.
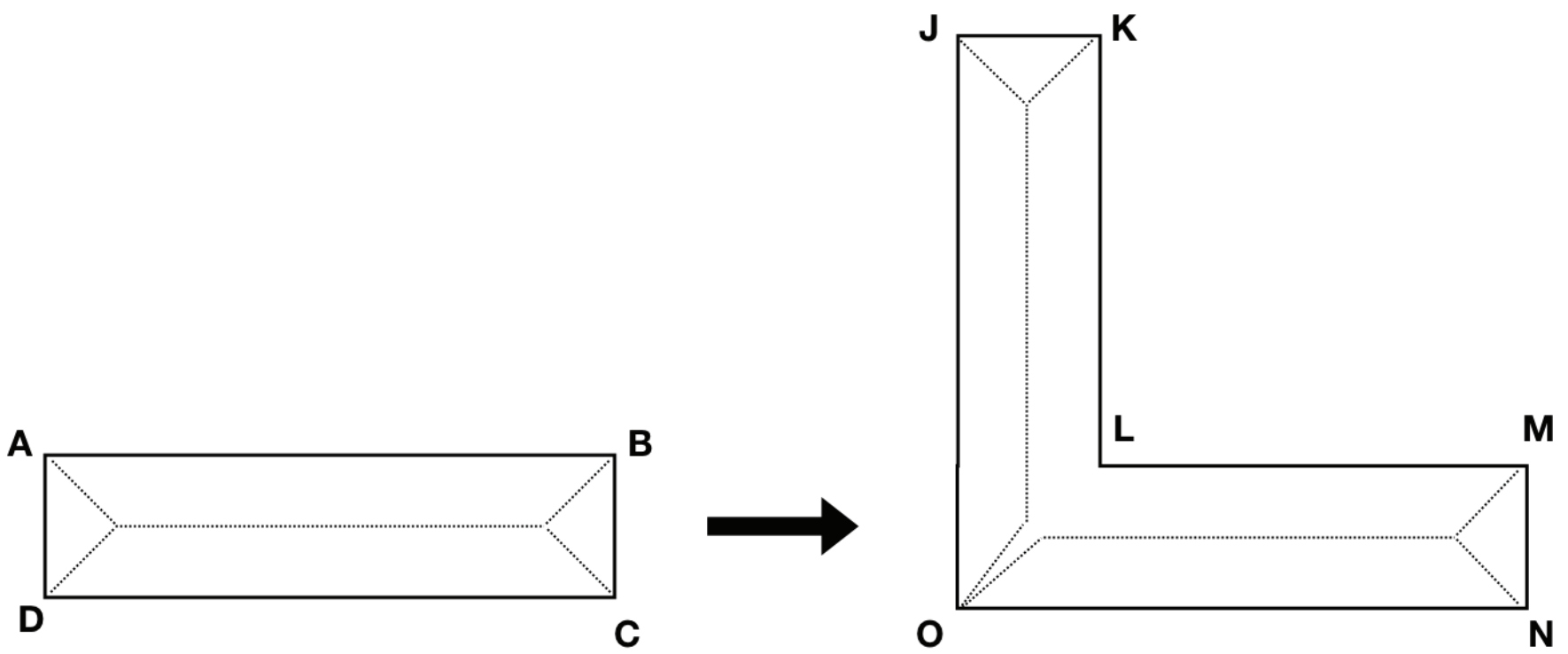
in the field and the laboratory it is extremely difficult to ensure that the goal location is not visible from a supposed novel start point (e.g., Gould, 1986; see Dyer, 1991), or to ensure that a novel route was not actually experienced during training (Morris, 1981; see Sutherland et al., 1987), making it difficult to infer that animals are able to navigate using a cognitive map (for review, see Pritchard \& Healy, 2017). A final point to make here is that apparent shortcutting behavior, another behavior predicted by cognitive map theory, might be explained by animals forming an associative chain while navigating a fixed route, based on S-S associations. According to Deutsch's (1960) theory, because the stimuli along a route are experienced in a fixed temporal order, each set of stimuli becomes associated with the next, and the final set of stimuli becomes associated with the goal. As the animal passes by each set of stimuli, the representation of the next is activated. If an opportunity to make a shortcut arises, then the animal will take it, not because it has a global representation of the relations among all of the stimuli in the environment but because the representation of a set of stimuli closer to the goal has been activated. Deutsch's theory actually incorporated many of Tolman's (1948) concepts and is able to account for a great deal of the spatial flexibility that O'Keefe and Nadel (1978) argued was key evidence for the existence of a global cognitive map. Yet O'Keefe and Nadel did not consider Deutsch's theory in their work (Dickinson, 1980). Despite this, a flaw in Deutsch's theory is that it is essentially nonspatial. We have seen compelling evidence that animals do represent distances and directions among cues in their environments, and an associative account of what is learned in spatial learning must incorporate this. It may be that the most complex and abstract kinds of spatial representation are beyond what associative learning theory can currently accommodate, but the evidence for such representations is certainly not always consistent, as we have seen. In the second part of the article, I turn to the conditions of learning.

\section{Discrimination of Stimuli}

An early account of a major difference between spatial learning and associative learning was that the former was incidental, whereas the latter depended on reinforcement. We have seen that this is a rather outdated distinction, to the point that it may be called a fallacy. It does seem to be the case, however, that exploration is a necessary condition for spatial learning, so it is worth considering what associative processes might be at play while an animal explores its environment (see, e.g., Ellen, Soteres, \& Wages, 1984; Sutherland et al., 1987). One reason that exploration might be important is that it increases the exposure to stimuli in the environment, which in turn may modulate their discriminability via a process of perceptual learning. A well-known consequence of exposure to a stimulus without a resulting biologically relevant event, such as food, is known as latent inhibition - a retardation of subsequent learning when the stimulus does indicate an important event (Lubow, 1973; Lubow \& Weiner, 2010). However, exposure to more than one stimulus is sometimes found to actually facilitate subsequent discrimination between them (E. J. Gibson \& Walk, 1956; Hall, 1991; McLaren \& Mackintosh, 2000). McLaren and Mackintosh (2000) proposed several associative mechanisms that could lead to perceptual learning, including latent inhibition of common elements, and mutual inhibition of unique elements. Their account predicted that exposure to stimuli would facilitate subsequent discrimination most when the stimuli were more similar to each other but that latent inhibition would be more evident when there was a greater perceptual difference between stimuli. Such a prediction has been borne out in studies of spatial learning (e.g., Chamizo \& Mackintosh, 1989; Trobalon, Chamizo, \& Mackintosh, 1992). Trobalon, Sansa, Chamizo, and Mackintosh (1991) preexposed two groups of rats to two different arms in a radial arm maze. For one group the arms were separated by $135^{\circ}$, so the views of the room cues from the ends of these arms were very different. For the other group the arms were separated by only $45^{\circ}$, meaning that the views from the arms were rather similar and the discrimination therefore more difficult. Compared with a control group that did not receive preexposure, the preexposed group with the easy discrimination failed to show any effects of perceptual learning once one of the arms was baited with food, but the group with the difficult discrimination did, with the rats subsequently learning to run to the baited arm with fewer errors than the control group.

Conversely, Rodrigo, Chamizo, McLaren, and Mackintosh (1994) showed that preexposure to landmark cues surrounding a radial arm maze enhanced subsequent discrimination of the arms in a learning task if the exposed views were common to the various arms. However, if the exposed views were unique to the correct and incorrect arms in the later discrimination task, the acquisition was impaired, consistent with a latent inhibition effect. This retardation of learning in the spatial domain is an outcome that O'Keefe and Nadel's (1978)

COMPARATIVE COGNITION \& BEHAVIOR REVIEWS 
cognitive mapping theory cannot predict, because exploration of an environment in that account is expected to lead to the buildup of a cognitive map. That is, according to a cognitive map account, the preexposure to the environment should only facilitate later discrimination.

\section{Changes in Attention}

The effects of exploration of stimuli not only are evident from studies of perceptual learning but also may be observed by subsequent changes of attention to different cues in the environment. Several authors have proposed that the attention paid to a stimulus increases if it reliably predicts a significant outcome and that the stimulus is subsequently more likely to enter into a new association if the opportunity arises (e.g., George \& Pearce, 1999; Le Pelley, 2004; Mackintosh, 1975; Mackintosh \& Sutherland, 1971). Testing this account is an extremely active and fruitful area of research in associative learning and has been very influential in how we consider humans to learn (e.g., Le Pelley, Mitchell, Beesley, George, \& Wills, 2016), but few studies have examined this idea in spatial learning. One study using the water maze has shown results consistent with the idea that prior experience with a cue influences its future associability. Prados, Redhead, and Pearce (1999) trained rats to swim to a submerged platform that had a stick attached to it. In addition, four landmarks were positioned around the periphery of the pool, inside a curtain that blocked from view the rest of the testing room. At the end of training, test trials were conducted in which the stick was removed from the platform but the landmarks remained present. For Group Stable-Same, and Group Stable-Diff, the positions of the landmarks remained in the same positions throughout training, meaning that they were, in addition to the stick, reliable indicators of the position of the platform. Another group - Group Mix - was trained in a similar way to the other two groups, but between every trial the configuration of landmarks was changed, so they did not provide reliable information about where the platform was located. During the test trials, the landmarks were in the same configuration as during training for Group Stable-Same but were in a new configuration for Group Stable-Diff. Despite this, both groups located the platform in a similar time to each other, and considerably faster than Group Mix. The results are consistent with the notion that during training for Group StableDiff, attention paid to the landmarks increased so that they were readily able to enter into a new association with the platform position after their configuration was altered during the test. The results cannot be explained by the idea put forward in the previous section - that discriminability of the landmarks increased as a result of their exposure-because the same effect should have been observed for Group Mix. They are also difficult to account for by appealing to successful navigation depending on the formation of a cognitive map.

Further evidence for the role that attention plays in spatial learning comes from demonstrations of intradimensional extradimensional shift effects that are considered a hallmark of the associative learning theories involving changes to attention (e.g., Buckley, Smith, \& Haselgrove, 2014; Cuell, Good, Dopson, Pearce, \& Horne, 2012; Trobalon, Miguelez, McLaren, \& Mackintosh, 2003).

\section{Cue Competition}

One of the phenomena most closely connected with associative learning is cue competition. Cue competition may be defined as occurring when behavioral control from one stimulus is restricted by prior or concurrent learning to another; it is significant in relation to spatial learning because so many sources of spatial information are available to animals that some have argued that learning based on this redundancy must involve independent modules (e.g., Cheng, 1986; Gallistel, 1990; Jeffery, 2010). Although the development of new modules over the modification of old ones makes sense from an evolutionary perspective (Shettleworth, 2010), the question of how such modules control the progression of spatial learning remains open. One characteristic of modularity is that modules are said to be encapsulated (Fodor, 1983); that is, information processed within a module is impenetrable to information stored outside the module. If this is the case with spatial processing modules, then cue competition should not be expected within spatial learning. It is difficult to say whether different spatial strategies, such as using magnetic cues, sun compass, path integration, olfaction, or landmarks, are processed in competition with one another, as predicted by an associative account, or if they are processed in parallel, or even hierarchically. Shettleworth (2010) argued that parallel processing would make sense, as different strategies can act as backups for one another when other strategies are unavailable. In reference to the preceding list of strategies, pigeons might make use of olfactory cues when the sun compass is unavailable (Keeton, 1974). The evidence to date points also to parallel processing 
of path integration (when animals maintain a vector between their current location and a home base) and learning based on landmarks (Shettleworth \& Sutton, 2005), and there is little evidence that response and place learning strategies are in competition with one another (B. M. Gibson \& Shettleworth, 2005). Cheng, Shettleworth, Huttenlocher, and Rieser (2007) suggested that in cases such as these, one strategy is necessary for the development of learning based on the other. However, evidence from ant and bee navigation suggests that independent modules for path integration, orientation from surrounding panoramic views, and systematic search strategies, previously thought to act in sequence, are actually integrated to form optimal hierarchical navigational strategies (Hoinville \& Wehner, 2018; Wehner, Hoinville, Cruse, \& Cheng, 2016).

In some circumstances, however, it is possible to assess cue competition. In particular, one influential theory of navigation by O'Keefe and Nadel (1978) argues that the formation of a cognitive map occurs incidentally, driven by exploration of the environment, rather than by associative rules. The addition of new information to the cognitive map should occur regardless of experience with other cues within the map. Thus, the presence or otherwise of cue competition in spatial learning tasks that are said to engage a cognitive map is fundamental to our understanding of whether spatial learning is under the control of associative processes.

A number of excellent reviews have documented evidence for cue competition effects in spatial learning (e.g., Chamizo, 2003; Pearce, 2009; Shettleworth, 2010). Blocking, in which prior learning restricts learning about a newly introduced cue, and overshadowing, in which concurrent learning about two or more cues results in restricted learning about each, have been demonstrated both between proximal landmarks (e.g., Rodrigo, Chamizo, McLaren, \& Mackintosh, 1997; SanchezMoreno, Rodrigo, Chamizo, \& Mackintosh, 1999; Sansa \& Prados, 2003) and between proximal and distal landmarks (e.g., Diez-Chamizo, Sterio, \& Mackintosh, 1985; March, Chamizo, \& Mackintosh, 1992; Roberts \& Pearce, 1998). In the case of Roberts and Pearce (1998), learning the position of a platform in a water maze with reference to distal room cues was considerably weakened if rats had prior experience of finding the platform with a beacon attached before the room cues were revealed. This result is particularly surprising, as learning based on the room cues has been argued to engage a cognitive map, whereas navigating with reference to a beacon does not (Morris, 1981; Morris, Garrud, Rawlins, \& O’Keefe,
1982). It raises a question over the use of the cognitive map hypothesis as a distinct psychological representation from those governed by associative processes.

A notable case, in which cue competition was at first difficult to demonstrate, was the geometric module hypothesis. Cheng (1986) proposed that animals displayed a primacy for extracting the broad geometric layout of the environment when they were first required to orient within it. Furthermore, they did this despite the presence of nongeometric features that, under some conditions, could provide more reliable information for orientation. Studies followed demonstrating this effect from fish to human infants (reviewed in Cheng \& Newcombe, 2005). From the notion of an encapsulated geometric module follows the prediction that the representation of environmental geometry will be unaffected by prior or concurrent training based on nongeometric features, such as wall color or discrete landmarks. Certain studies in rats reported a failure to demonstrate either blocking or overshadowing of geometry by featural cues (e.g., Hayward, Good, \& Pearce, 2004; Hayward, McGregor, Good, \& Pearce, 2003; McGregor, Horne, Esber, \& Pearce, 2009; Pearce, Ward-Robinson, Good, Fussell, \& Aydin, 2001; Wall, Botly, Black, $\&$ Shettleworth, 2004). However, first in black-capped chickadees (Gray, Bloomfield, Ferrey, Spetch, \& Sturdy, 2005), then in rats (Pearce, Graham, Good, Jones, \& McGregor, 2006), it was shown that wall color restricted learning based on geometry. Subsequently, the same cue competition effects were shown for discrete landmarks restricting learning based on geometry (e.g., rats: Horne \& Pearce, 2009; Kosaki, Austen, \& McGregor, 2013; humans: Wilson \& Alexander, 2008) and for cue competition between entirely geometric cues (e.g., humans: Prados, 2011; Redhead \& Hamilton, 2009).

An examination of the peculiar difficulties in demonstrating cue competition with geometric cues reveals the importance of the relative salience of geometric and nongeometric cues. One strand of this evidence comes from studies in which male and female rats were compared in the extent to which they relied on geometric and nongeometric information. Pioneering work by Williams, Barnett, and Meck (1990) and Williams and Meck (1991) established that female rats have a clear tendency to use landmarks, such as objects around a room or posters on walls, when solving spatial tasks, whereas male rats tend to use geometric cues, such as the shape of the testing room. This finding was replicated in a swimming pool by Rodríguez, Torres, Mackintosh, and Chamizo (2010), who argued that these

COMPARATIVE COGNITION \& BEHAVIOR REVIEWS 
differences reflected differences in cue salience to males and females. Rodríguez, Chamizo, and Mackintosh (2011) then showed that these differences in salience made a striking difference in the extent to which landmarks could block or overshadow geometry, finding that learning based on geometry seemed impervious to learning based on a landmark for male rats but that for female rats the opposite was true, consistent with the differential salience of these cues for the two sexes. The other strand of evidence comes from studies in which the salience of landmark or geometry cues was manipulated by the experimenter rather than by evolution. Both the salience of the geometric cue (Kosaki et al., 2013) and the landmark cue (Austen, Kosaki, \& McGregor, 2013; Chamizo, Rodrigo, Peris, \& Grau, 2006; Horne \& Pearce, 2011) determine the extent to which cue competition is observed.

Under some circumstances this cue salience effect has led to the surprising facilitation of geometry learning by the simultaneous presence of a landmark (Cole,
Gibson, Pollack, \& Yates, 2011; Horne \& Pearce, 2011: rats) or feature (Kelly, 2010: Clark's nutcrackers; Pearce et al., 2006: rats). This effect, too, seems to be related to the relative salience of landmarks/features and geometry cues. Horne and Pearce (2011) showed that when the landmark cue is particularly salient compared with geometry, overshadowing is observed. When it is of relatively weak salience compared with geometry, geometry learning is enhanced. The effect seems to be modulated by the presence of within-compound associations that form between the landmark and geometry cues, with the relative expression of these associations, alongside direct associations between the geometry and the platform and the landmark and the platform, determining the effect observed. This analysis was given support by the results of an experiment reported by Austen et al. (2013; see Figure 6). They trained rats to find a platform in one corner of a triangular pool. In addition to the geometric cues provided by the shape of the pool, the rats could discriminate the corners based

Figure 6. Schematic diagram of the design used by Austen et al. (2013). Rats were trained to find the platform in one corner of the triangle (indicated by $\mathrm{a}+$ ) and could use the landmarks to distinguish the corners as well as the unique geometric properties of the walls in each corner (left panel). In the landmark stage, for one group the contingency between the platform and the landmarks was reversed (reversal treatment), and it was maintained for the other (middle panel). During tests, in extinction and with no landmarks present, the ability of each of the groups to discriminate the geometric cues was evaluated. Despite both groups experiencing the same contingencies between geometry and reinforcement, the reversal group discriminated significantly less well than the no reversal group.

\section{Training stage Landmarks + geometry \\ Landmark stage}

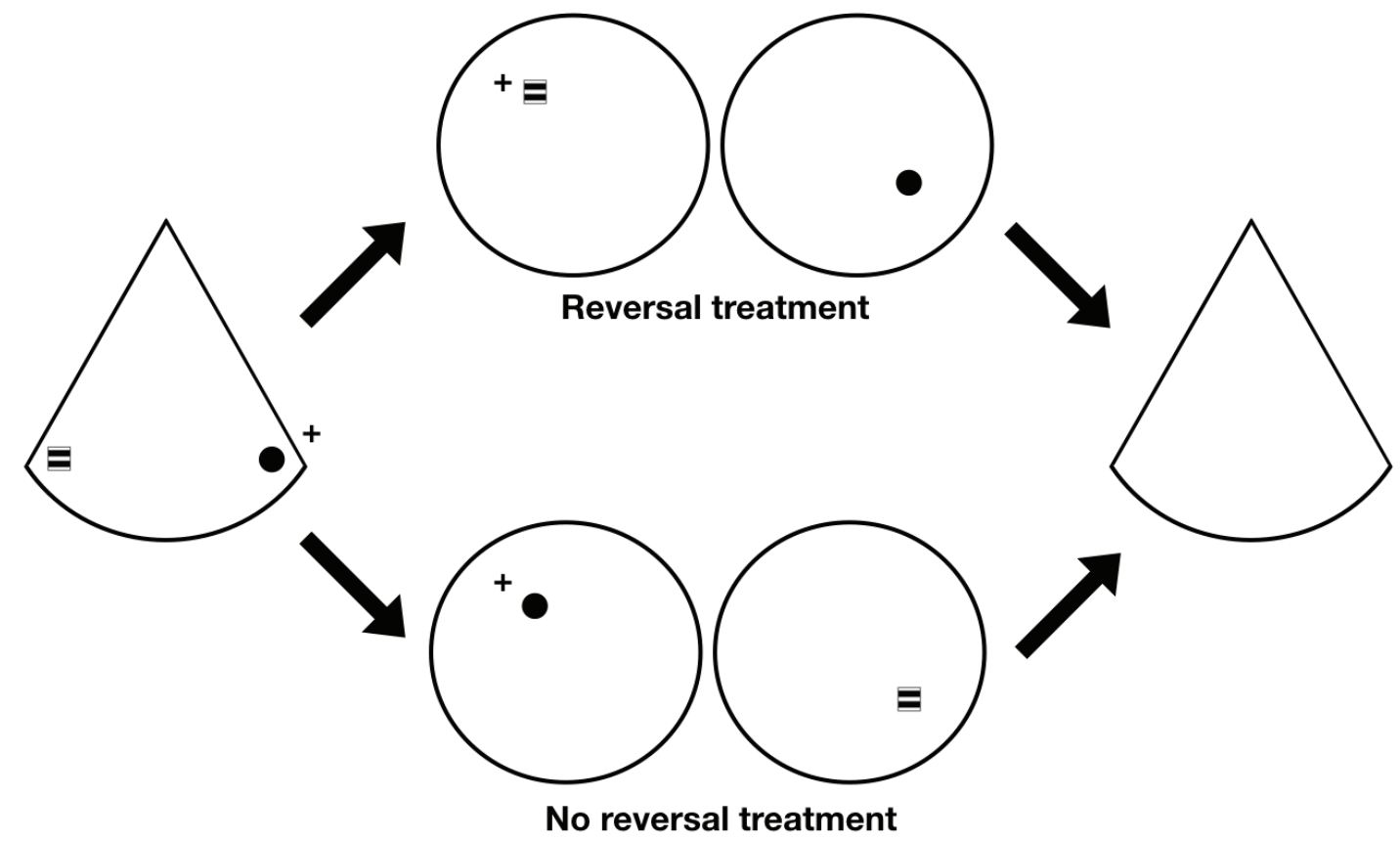


on the features of the landmark that occupied that corner. Later, reversing the contingency between the landmarks and the platform in a circular pool correspondingly diminished discrimination based on geometry when the rats were finally tested in the triangular pool. The results indicate that the sight of the geometric cues associated with the platform also evoked a representation of the landmark that was previously associated with those geometric cues. For those rats that underwent reversal training, the discrimination of geometry was weakened by the revalued within-compound association.

The results from these studies of cue competition in both landmark learning cognitive map tasks (e.g., Morris, 1981) and geometry learning tasks (e.g., Cheng, 1986) have failed to support the hypothesis that spatial learning progresses by some nonassociative rule. Instead, the failure to demonstrate cue competition can be explained by differences in the relative salience of cues (Kosaki et al., 2013; Rodríguez et al., 2011), or the compensatory effects of within-compound associations (Austen et al., 2013; Horne \& Pearce, 2011), which are effects all explained by principles of associative learning.

\section{Challenges and Priorities}

The effects discussed in this article may be general across species, but it is not possible to claim this with a great deal of certainty. The reviewed literature does not cover a great variety of taxa, and the field must address this problem. Even in relation to the (mostly rodent) species discussed, most of the work has been conducted with only one sex - the male. A number of authors have discussed the importance of considering sex differences in cognition and neuroscience (e.g., Cahill, 2006; Kimura, 2000), so the field must address this problem in the future. In relation to testing a wider range of taxa, one problem might be the friction between internal and external validity. Psychologists concerned with associative learning theory have tended to confine their interest to a few well-studied species in a few well-understood paradigms. To a large extent this suits their objective of conducting extremely well-controlled experiments. However, it also limits the generality of their conclusions, so an attempt to conduct the kinds of experiments discussed in this article with a wider range of species is a challenge to the field.

Equally, although the conditions under which spatial learning progresses is well studied and characterized, and the nature of the associations formed in spatial learning, are reasonably well understood (albeit with some questions over the evidence for the most complex metric representations), this article has had little to say about how learning is translated into performance. Certain mechanisms have been proposed in simpler models for how animals minimize the discrepancy between the animal's current view and one held in memory. For example, a view-matching mechanism first proposed in bees (Cartwright \& Collett, 1983) has been used with some success to explain various behavioral results in rats navigating in geometrically distinct environments (Cheung, Stürzl, Zeil, \& Cheng, 2008; Stürzl, Cheung, Cheng, \& Zeil, 2008). Although such accounts may be able to model accurate navigation in these environments, they are unable to explain all of the reports of cue competition and facilitation just discussed. They are, essentially, taxon learning models, as are a number of "servomechanism" models (reviewed in Cheng, 2006) that provide a set of algorithms to translate learning to motor output. However, models that have attempted to explain the output of the neurons thought to underlie cognitive mapping (Poulter et al., 2018) have not always produced truly maplike results either. For example, Brown and Sharp (1995) proposed an S-R mechanism that depended on hypothetical roles for place cells and head direction cells but that limited the animal to a fixed path. More flexible is the model by Burgess, Recce, and O'Keefe (1994), which couples the activity of place cells to hippocampal theta rhythm. As the animal explores its environment, the firing of place cells in the animal's path is linked to the activity of hypothetical goal cells. The output of these goal cells enables to animal to estimate the distance and direction to the goal from anywhere along the path. Although this model provides a more flexible mechanism than Brown and Sharp's (1995), it relies on the action of neural units that have not yet been shown to exist. To better account for the associative effects previously discussed, Miller and Shettleworth (2007) proposed tying a performance rule to an associative learning rule. The tendency to navigate to a location was directly related to the strength of an association between a cue and an outcome, and the model was able to account for many of the associative effects described earlier in this article. But the predictions of the circumstances under which these effects should occur have not always been supported by experimental evidence (Austen et al., 2013; Horne \& Pearce 2011; McGregor et al., 2009). Clearly an account is required that can incorporate the output of learning to performance but also incorporates our knowledge about the neural basis of spatial behavior and the associative phenomena that demonstrate how learning progresses.

COMPARATIVE COGNITION \& BEHAVIOR REVIEWS 
Before this is possible, however, a serious attempt must be made to better understand the link between the neural and psychological bases of spatial learning. At present, these literatures seem largely to progress independent of one another, as though evidence from one has no bearing on research in the other. Although understanding the neural basis of instrumental and Pavlovian conditioning seems to be a healthy and active pursuit (Johansson, Jirenhed, Rasmussen, Zucca, \& Hesslow, 2014; Lingawi, Dezfouli, \& Balleine, 2016), this seems to be less of a priority in spatial learning. However, a complete account will not be possible until we can understand the neural basis of psychological effects and explain the psychological effects in terms of neural activity.

\section{Conclusions}

Perhaps associative learning theory has suffered from a deep misunderstanding in the wider psychological community. This misunderstanding is based on a view that associative learning is synonymous with the views of early behaviorists and with S-R theory. However, as we have seen, modern associative learning has long had to account for goal-directedness, and a specific branch of study has concerned itself with developing behavioral assays to record goal-directed action. I have argued that these same assays may be applied to spatial learning and that they reveal the same distinction between habitlike behaviors and goal-directedness. Another way of conceptualizing this goal-directedness is as stimulusstimulus associations, and I have demonstrated the existence of these S-S associations between cues in the spatial environment as well as between a stimulus and an outcome. In particular, learning vectors among landmarks in the environment provides a particularly rich representation of the relations among stimuli, though I have argued that this does not necessarily compel us to accept that animals possess cognitive maps. To examine the notion of cognitive maps further, I examined the claim that cognitive maps are acquired via a distinctive nonassociative mechanism. This mechanism has been said to be based on active exploration of the environment and is incidental in nature. Although the importance of exploration is not in doubt, I argued that its importance was not necessarily because it engaged a nonassociative mechanism, as S-R theory had already been demonstrated as an inadequate representation of associative learning theory. Instead, I demonstrated that distinctively associative phenomena such as latent inhibition, perceptual learning, and changes in attention could explain why exploration is an important condition for spatial learning. Finally, I examined the claim that spatial learning is an example of cognitive modularity by testing whether it is immune to cue competition effects. We saw that spatial learning conforms to the expectation of associative learning theories, being subject to the same domain-general competitive algorithms as demonstrated in nonspatial associative tasks. Although this review is necessarily limited in its scope, it provides an associationist's view of many of the phenomena that have been claimed to be unique to spatial learning and shows a formal correspondence between spatial and nonspatial learning.

\section{References}

Adams, C. D., \& Dickinson, A. (1981). Instrumental responding following reinforcer devaluation. Quarterly Journal of Experimental Psychology Section B-Comparative and Physiological Psychology, 33, 109-121. doi:10.1080/14640748108400816

Ambosta, A. H., Reichert, J. F., \& Kelly, D. M. (2013). Reorienting in virtual 3D environments: Do adult humans use principal axes, medial axes or local geometry? PLOS ONE, 8(11), Article e78985. doi:10.1371/journal.pone.0078985

Austen, J. M., Kosaki, Y., \& McGregor, A. (2013). Within-compound associations explain potentiation and failure to overshadow learning based on geometry by discrete landmarks. Journal of Experimental Psychology-Animal Behavior Processes, 39(3), 259-272. doi:10.1037/A0032525

Balleine, B. W., \& Dickinson, A. (1998). Goaldirected instrumental action: Contingency and incentive learning and their cortical substrates. Neuropharmacology, 37(4-5), 407-419. doi:10.1016/S0028-3908(98)00033-1

Bennett, A. T. D. (1996). Do animals have cognitive maps? Journal of Experimental Biology, 199(1), 219-224.

Biegler, R., McGregor, A., \& Healy, S. D. (1999). How to animals 'do' geometry? Animal Behaviour, 57(3), F4-F8. doi:10.1006/anbe.1998.1003 
Blaisdell, A. P., \& Cook, R. G. (2005). Integration of spatial maps in pigeons. Animal Cognition, 8(1), 7-16. doi:10.1007/S10071-004-0223-1

Blodgett, H. C. (1929). The effect of the introduction of reward upon the maze performance of rats. University of California Publications in Psychology, 4, 113-134.

Bodily, K. D., Eastman, C. K., \& Sturz, B. R. (2011). Neither by global nor local cues alone: Evidence for a unified orientation process. Animal Cognition, 14(5), 665-674. doi:10.1007/S10071-011-0401-X

Bouchekioua, Y., Miller, H. C., Craddock, P., Blaisdell, A. P., \& Molet, M. (2013). Spatial integration of boundaries in a $3 \mathrm{D}$ virtual environment. Acta Psychologica, 144(2), 316-323. doi:10.1016/j.actpsy.2013.06.015

Brown, M. A., \& Sharp, P. E. (1995). Simulation of spatial-learning in the morris water maze by a neural-network model of the hippocampalformation and nucleus-accumbens. Hippocampus, 5(3), 171-188. doi:10.1002/Hipo.450050304

Buckley, M. G., Smith, A. D., \& Haselgrove, M. (2014). Shape shifting: Local landmarks interfere with navigation by, and recognition of, global shape. Journal of Experimental PsychologyLearning Memory and Cognition, 40(2), 492-510. doi:10.1037/a0034901

Buckley, M. G., Smith, A. D., \& Haselgrove, M. (2016). Thinking outside of the box: Transfer of shape-based reorientation across the boundary of an arena. Cognitive Psychology, 87, 53-87. doi:10.1016/j.cogpsych.2016.04.001

Burgess, N., Recce, M., \& O’Keefe, J. (1994). A model of hippocampal function. Neural Networks, 7(6-7), 1065-1081. doi:10.1016/S0893-6080(05)80159-5

Cahill, L. (2006). Why sex matters for neuroscience. Nature Reviews Neuroscience, 7(6), 477-484. doi:10.1038/nrn1909
Carr, H., \& Watson, J. B. (1908). Orientation in the white rat. Journal of Comparative Neurology and Psychology, 18(1), 27-44. doi:10.1002/Cne.920180103

Cartwright, B. A., \& Collett, T. S. (1983). Landmark learning in bees-Experiments and models. Journal of Comparative Physiology, 151(4), 521-543. doi:10.1007/BF00605469

Chamizo, V. D. (2003). Acquisition of knowledge about spatial location: Assessing the generality of the mechanism of learning. Quarterly Journal of Experimental Psychology Section B, 56(1), 102-113. doi:10.1080/02724990244000205

Chamizo, V. D., \& Mackintosh, N. J. (1989). Latent Learning and latent inhibition in maze discriminations. Quarterly Journal of Experimental Psychology Section B-Comparative and Physiological Psychology, 41(1), 21-31.

Chamizo, V. D., Rodrigo, T., \& Mackintosh, N. J. (2006). Spatial integration with rats. Learning \& Behavior, 34(4), 348-354. doi:10.3758/Bf03193198

Chamizo, V. D., Rodrigo, T., Peris, J. M., \& Grau, M. (2006). The influence of landmark salience in a navigation task: An additive effect between its components. Journal of Experimental PsychologyAnimal Behavior Processes, 32(3), 339-344. doi:10.1037/0097-7403.32.3.339

Cheeseman, J. F., Millar, C. D., Greggers, U., Lehmann, K., Pawley, M. D. M., Gallistel, C. R., . . . Menzel, R. (2014). Way-finding in displaced clock-shifted bees proves bees use a cognitive map. Proceedings of the National Academy of Sciences of the United States of America, 111(24), 8949-8954. doi:10.1073/pnas.1408039111

Cheng, K. (1986). A purely geometric module in the rats spatial representation. Cognition, 23(2), 149-178. doi:10.1016/0010-0277(86)90041-7

Cheng, K. (1989). The vector sum model of pigeon landmark use. Journal of Experimental Psychology-Animal Behavior Processes, 15(4), 366-375. doi:10.1037/0097-7403.15.4.366 
Cheng, K. (1995). Landmark-based spatial memory in the pigeon. Psychology of Learning and Motivation, 33, 1-21. doi:10.1016/S0079-7421(08)60370-9

Cheng, K. (2006). Arthropod navigation: Ants, bees, crabs, spiders finding their way. In E. A. Wasserman \& T. R. Zentall (Eds.), The Oxford handbook of comparative cognition (pp. 189-209). New York, NY: Oxford University Press. doi:10.1093/acprof:oso/9780195377804.003.0011

Cheng, K. (2012). Arthropod navigation: Ants, bees, crabs, spiders finding their way. In E. A. Wasserman \& T. R. Zentall (Eds.), The Oxford handbook of comparative cognition (2nd ed., pp. 347-365). New York, NY: Oxford University Press. doi:10.1093/oxfordhb/9780195392661.013.0019

Cheng, K., \& Gallistel, C. R. (2005). Shape parameters explain data from spatial transformations: Comment on Pearce et al. (2004) and Tommasi \& Polli (2004). Journal of Experimental PsychologyAnimal Behavior Processes, 31(2), 254-259. doi:10.1037/0097-7403.31.2.254

Cheng, K., \& Newcombe, N. S. (2005). Is there a geometric module for spatial orientation? Squaring theory and evidence. Psychonomic Bulletin \& Review, 12(1), 1-23. doi:10.3758/BF03196346

Cheng, K., Shettleworth, S. J., Huttenlocher, J., \& Rieser, J. J. (2007). Bayesian integration of spatial information. Psychological Bulletin, 133(4), 625-637. doi:10.1037/0033-2909.133.4.625

Cheng, K., \& Spetch, M. L. (1998). Mechanisms of landmark use in mammals and birds. In S. D. Healy (Ed.), Spatial representation in animals (pp. 1-17). Oxford, England: Oxford University Press.

Cheng, K., Spetch, M. L., Kelly, D. M., \& Bingman, V. P. (2006). Small-scale spatial cognition in pigeons. Behavioral Processes, 72(2), 115-127. doi:10.1016/j.beproc.2005.11.018
Cheung, A., Stürzl, W., Zeil, J., \& Cheng, K. (2008). The information content of panoramic images II: view-based navigation in nonrectangular experimental arenas Journal of Experimental Psychology-Animal Behavior Processes, 34(1), 15-30. doi:10.1037/0097-7403.34.1.15

Cole, M. R., Gibson, L., Pollack, A., \& Yates, L. (2011). Potentiation and overshadowing of shape by wall color in a kite-shaped maze using rats in a foraging task. Learning and Motivation, 42(2), 99-112. doi:10.1016/J.Lmot.2010.11.001

Collett, M., Chittka, L., \& Collett, T. S. (2013). Spatial memory in insect navigation. Current Biology, 23(17), R789-R800. doi:10.1016/j.cub.2013.07.020

Collett, T. S., Cartwright, B. A., \& Smith, B. A. (1986). Landmark learning and visuospatial memories in gerbils. Journal of Comparative Physiology A: Sensory Neural and Behavioral Physiology, 158(6), 835-851. doi:10.1007/BF01324825

Collett, T. S., \& Zeil, J. (2018). Insect learning flights and walks. Current Biology, 28(17), R984-R988. doi:10.1016/j.cub.2018.04.050

Colwill, R. M., \& Rescorla, R. A. (1986). Associative structures in instrumental learning. Psychology of Learning and MotivationAdvances in Research and Theory, 20, 55-104. doi:10.1016/S0079-7421(08)60016-X

Cook, R. G., \& Blaisdell, A. P. (2006). Short-term item memory in successive same-different discriminations. Behavioral Processes, 72(3), 255-264. doi:10.1016/j.beproc.2006.03.013

Cuell, S. F., Good, M. A., Dopson, J. C., Pearce, J. M., \& Horne, M. R. (2012). Changes in attention to relevant and irrelevant stimuli during spatial learning. Journal of Experimental PsychologyAnimal Behavior Processes, 38(3), 244-254. doi:10.1037/A0028491 
De Leonibus, E., Costantini, V. J. A., Massaro, A., Mandolesi, G., Vanni, V., Luvisetto, S., . . Mele, A. (2011). Cognitive and neural determinants of response strategy in the dual-solution plusmaze task. Learning \& Memory, 18(4), 241-244. doi:10.1101/lm.2074311

Deutsch, J. A. (1960). The structural basis of behavior. Cambridge, England: Combridge University Press.

Dickinson, A. (1980). The hippocampus as a cognitive map [Book review]. Quarterly Journal of Experimental Psychology, 32, 349-350.

Dickinson, A. (1985). Actions and habits-The development of behavioral autonomy. Philosophical Transactions of the Royal Society of London Series B-Biological Sciences, 308(1135), 67-78. doi:10.1098/rstb.1985.0010

Dickinson, A., \& Balleine, B. (1994). Motivational control of goal-directed action. Animal Learning \& Behavior, 22(1), 1-18. doi:10.3758/Bf03199951

Diez-Chamizo, V., Sterio, D., \& Mackintosh, N. J. (1985). Blocking and overshadowing between intra-maze and extra-maze cues - A test of the independence of locale and guidance learning. Quarterly Journal of Experimental Psychology Section B-Comparative and Physiological Psychology, 37(3), 235-253. doi:10.1080/14640748508402098

Doeller, C. F., \& Burgess, N. (2008). Distinct errorcorrecting and incidental learning of location relative to landmarks and boundaries. Proceedings of the National Academy of Sciences of the United States of America, 105(15), 5909-5914. doi:10.1073/Pnas.0711433105

Dyer, F. C. (1991). Bees acquire route-based memories but not cognitive maps in a familiar landscape. Animal Behavior, 41, 239-246. doi:10.1016/S0003-3472(05)80475-0

Ellen, P., Soteres, B. J., \& Wages, C. (1984). Problemsolving in the rat-Piecemeal acquisition of cognitive maps. Animal Learning \& Behavior, 12(2), 232-237. doi:10.3758/Bf03213147
Elliott, M. H. (1928). The effect of change of reward on the maze performance of rats. University of California Publications in Psychology, 4, 19-30.

Fodor, J. A. (1983). The modularity of mind. Cambridge, MA: MIT Press. doi:10.7551/mitpress/4737.001.0001

Gallistel, C. R. (1990). The organization of learning. Cambridge, MA: MIT Press.

George, D. N., \& Pearce, J. M. (1999). Acquired distinctiveness is controlled by stimulus relevance not correlation with reward. Journal of Experimental PsychologyAnimal Behavior Processes, 25(3), 363-373. doi:10.1037/0097-7403.25.3.363

Gibson, B. M., \& Shettleworth, S. J. (2005). Place versus response learning revisited: Tests of blocking on the radial maze. Behavioral Neuroscience, 119(2), 567-586. doi:10.1037/0735-7044.119.2.567

Gibson, E. J., \& Walk, R. D. (1956). The effect of prolonged exposure to visually presented patterns on learning to discriminate them. Journal of Comparative and Physiological Psychology, 49(3), 239-242. doi:10.1037/h0048274

Gould, J. L. (1986). The locale map of honey-beesDo insects have cognitive maps. Science, 232(4752), 861-863. doi:10.1126/Science.232.4752.861

Gould-Beierle, K. L., \& Kamil, A. C. (1996). The use of local and global cues by Clark's nutcrackers, Nucifraga columbiana. Animal Behavior, 52, 519-528. doi:10.1006/anbe.1996.0194

Gray, E. R., Bloomfield, L. L., Ferrey, A., Spetch, M. L., \& Sturdy, C. B. (2005). Spatial encoding in mountain chickadees: Features overshadow geometry. Biology Letters, 1(3), 314-317. doi:10.1098/rsbl.2005.0347

Hafting, T., Fyhn, M., Molden, S., Moser, M. B., \& Moser, E. I. (2005). Microstructure of a spatial map in the entorhinal cortex. Nature, 436(7052), 801-806. doi:10.1038/Nature03721 
Hall, G. (1991). Perceptual and associative learning. Oxford, England: Clarendon Press. doi:10.1093/acprof:oso/9780198521822.001.0001

Hayward, A., Good, M. A., \& Pearce, J. M. (2004). Failure of a landmark to restrict spatial learning based on the shape of the environment. Quarterly Journal of Experimental Psychology Section BComparative and Physiological Psychology, 57(4), 289-314. doi:10.1080/02724990344000150

Hayward, A., McGregor, A., Good, M. A., \& Pearce, J. M. (2003). Absence of overshadowing and blocking between landmarks and the geometric cues provided by the shape of a test arena. Quarterly Journal of Experimental Psychology Section B-Comparative and Physiological Psychology, 56(1), 114-126. doi:10.1080/02724990244000214

Hoinville, T., \& Wehner, R. (2018). Optimal multiguidance integration in insect navigation. Proceedings of the National Academy of Sciences of the United States of America, 115(11), 2824-2829. doi:10.1073/pnas.1721668115

Horne, M. R., Gilroy, K. E., Cuell, S. F., \& Pearce, J. M. (2012). Latent spatial learning in an environment with a distinctive shape. Journal of Experimental Psychology-Animal Behavior Processes, 38(2), 139-147. doi:10.1037/A0027288

Horne, M. R., \& Pearce, J. M. (2009). A landmark blocks searching for a hidden platform in an environment with a distinctive shape after extended pretraining. Learning \& Behavior, 37(2), 167-178. doi:10.3758/Lb.37.2.167

Horne, M. R., \& Pearce, J. M. (2011). Potentiation and overshadowing between landmarks and environmental geometric cues. Learning \& Behavior 39(4), 371-382. doi:10.3758/S13420-011-0032-8

Hull, C. L. (1943). Principles of behavior. New York, NY: Appleton-Century-Crofts.

Jeffery, K. J. (2010). Theoretical accounts of spatial learning: A neurobiological view (commentary on Pearce, 2009). Quarterly Journal of Experimental Psychology, 63(9), 1683-1699. doi:10.1080/17470210903540771
Johansson, F., Jirenhed, D. A., Rasmussen, A., Zucca, R., \& Hesslow, G. (2014). Memory trace and timing mechanism localized to cerebellar Purkinje cells. Proceedings of the National Academy of Sciences of the United States of America, 111(41), 14930-14934. doi:10.1073/pnas.1415371111

Kamil, A. C., \& Cheng, K. (2001). Way-finding and landmarks: The multiple-bearings hypothesis. Journal of Experimental Biology, 204(1), 103-113.

Kamil, A. C., \& Jones, J. E. (2000). Geometric rule learning by Clark's nutcrackers (Nucifraga columbiana). Journal of Experimental PsychologyAnimal Behavior Processes, 26(4), 439-453. doi:10.1037//0097-7403.26.4.439

Keeton, W. T. (1974). The orientational and navigational basis of homing in birds. In Advances in the Study of Behavior (Vol. 5, pp. 47-132). New York: Academic Press. doi:10.1016/S0065-3454(08)60020-0

Kelly, D. M. (2010). Features enhance the encoding of geometry. Animal Cognition, 13(3), 453-462. doi:10.1007/s10071-009-0296-y

Kelly, D. M., Chiandetti, C., \& Vallortigara, G. (2011). Re-orienting in space: Do animals use global or local geometry strategies? Biology Letters, 7(3), 372-375. doi:10.1098/Rsbl.2010.1024

Kimura, D. (2000). Sex and cognition. Cambridge, MA: MIT Press. doi:10.7551/mitpress/6194.001.0001

Kosaki, Y., Austen, J. M., \& McGregor, A. (2013). Overshadowing of geometry learning by discrete landmarks in the water maze: Effects of relative salience and relative validity of competing cues. Journal of Experimental PsychologyAnimal Behavior Processes, 39(2), 126-139. doi:10.1037/A003.1199

Kosaki, Y., Pearce, J. M., \& McGregor, A. (2018). The response strategy and the place strategy in a plusmaze have different sensitivities to devaluation of expected outcome. Hippocampus, 28(7), 484- 496. doi:10.1002/hipo.22847 
Krupic, J., Bauza, M., Burton, S., \& O'Keefe, J. (2018). Local transformations of the hippocampal cognitive map. Science, 359(6380), 1143-1145. doi:10.1126/science.aao4960

Leonard, B., \& McNaughton, B. (1990). Spatial representation in the rat: Conceptual, behavioral, and neurophysiological perspectives. In R. P. Kesner \& D. S. Olton (Eds.), Neurobiology of comparative cognition (pp. 363-422). Hillsdale, NJ: Erlbaum.

Le Pelley, M. E. (2004). The role of associative history in models of associative learning: a selective review and a hybrid model. Quarterly Journal of Experimental Psychology Section B-Comparative and Physiological Psychology, 57(3), 193-243. doi:10.1080/02724990344000141

Le Pelley, M. E., Mitchell, C. J., Beesley, T., George, D. N., \& Wills, A. J. (2016). Attention and associative learning in humans: An integrative review. Psychological Bulletin, 142(10), 1111-1140. doi:10.1037/bu10000064

Lew, A. R., Usherwood, B., Fragkioudaki, F., Koukoumi, V., Smith, S. P., Austen, J. M., \& McGregor, A. (2014). Transfer of spatial search between environments in human adults and young children (Homo sapiens): Implications for representation of local geometry by spatial systems. Developmental Psychobiology, 56(3), 421-434. doi:10.1002/Dev.21109

Lingawi, N. W., Dezfouli, A., \& Balleine, B. W. (2016). The psychological and physiological mechanisms of habit formation. In R. A. Murphy \& R. C. Honey (Eds.), The Wiley Handbook on the Cognitive Neuroscience of Learning (pp. 409-441). Chicester: Wiley.

Lubow, R. E. (1973). Latent inhibition. Psychological Bulletin, 79(6), 398-407. doi:10.1037/H0034425

Lubow, R. E., \& Weiner, I. (2010). Latent inhibition: Cognition, neuroscience and applications to schizophrenia. Cambridge, England: Cambridge University Press. doi:10.1017/CBO9780511730184

Mackintosh, N. J., \& Sutherland, S. (1971). Mechanisms of animal discrimination learning. New York:

Academic Press.
Mackintosh, N. J. (1975). Theory of attentionVariations in associability of stimuli with reinforcement. Psychological Review, 82(4), 276-298. doi:10.1037/h0076778

Mackintosh, N. J. (2002). Do not ask whether they have a cogntiive map, but how they find their way about. Psicologica, 23, 165-185.

March, J., Chamizo, V. D., \& Mackintosh, N. J. (1992). Reciprocal overshadowing between intramaze and extra-maze cues. Quarterly Journal of Experimental Psychology Section B-Comparative and Physiological Psychology, 45B(1), 49-63.

McGregor, A., Good, M. A., \& Pearce, J. M. (2004). Absence of an interaction between navigational strategies based on local and distal landmarks. Journal of Experimental PsychologyAnimal Behavior Processes, 30(1), 34-44. doi:10.1037/0097-7403.30.1.34

McGregor, A., Horne, M. R., Esber, G. R., \& Pearce, J. M. (2009). Absence of overshadowing between a landmark and geometric cues in a distinctively shaped environment: A test of miller and shettleworth (2007). Journal of Experimental Psychology-Animal Behavior Processes, 35(3), 357-370. doi:10.1037/A0014536

McGregor, A., Jones, P. M., Good, M. A., \& Pearce, J. M. (2006). Further evidence that rats rely on local rather than global spatial information to locate a hidden goal: Reply to Cheng and Gallistel (2005). Journal of Experimental PsychologyAnimal Behavior Processes, 32(3), 314-321. doi:10.1037/0097-7403.32.3.314

McLaren, I. P. L., \& Mackintosh, N. J. (2000). An elemental model of associative learning: I. Latent inhibition and perceptual learning. Animal Learning \& Behavior, 28(3), 211-246. doi:10.3758/Bf03200258

Miller, N. Y., \& Shettleworth, S. J. (2007). Learning about environmental geometry: An associative model. Journal of Experimental PsychologyAnimal Behavior Processes, 33(3), 191-212. doi:10.1037/0097-7403.33.3.191

COMPARATIVE COGNITION \& BEHAVIOR REVIEWS 
Molet, M., Jozefowiez, J., \& Miller, R. R. (2010). Integration of spatial relationships and temporal relationships in humans. Learning \& Behavior, 38(1), 27-34. doi:10.3758/Lb.38.1.27

Morris, R. G. M. (1981). Spatial localization does not require the presence of local cues. Learning and Motivation, 12(2), 239-260. doi:10.1016/0023-9690(81)90020-5

Morris, R. G. M., Garrud, P., Rawlins, J. N. P., \& O'Keefe, J. (1982). Place navigation impaired in rats with hippocampal-lesions. Nature, 297(5868), 681-683. doi:10.1038/297681a0

O'Keefe, J., \& Nadel, L. (1978). The hippocampus as a cogntive map. Oxford, England: Clarendon Press.

Packard, M. G., \& McGaugh, J. L. (1996). Inactivation of hippocampus or caudate nucleus with lidocaine differentially affects expression of place and response learning. Neurobiology of Learning and Memory, 65(1), 65-72. doi:10.1006/nlme.1996.0007

Pearce, J. M. (2009). The 36th Sir Frederick Bartlett lecture: An associative analysis of spatial learning. Quarterly Journal of Experimental Psychology (Hove), 62(9), 1665-1684. doi:10.1080/17470210902805589

Pearce, J. M., Good, M. A., Jones, P. M., \& McGregor, A. (2004). Transfer of spatial behavior between different environments: Implications for theories of spatial learning and for the role of the hippocampus in spatial learning. Journal of Experimental Psychology-Animal Behavior Processes, 30(2), 135-147. doi:10.1037/0097-7403.30.2.135

Pearce, J. M., Graham, M., Good, M. A., Jones, P. M., \& McGregor, A. (2006). Potentiation, overshadowing, and blocking of spatial learning based on-the shape of the environment.

Journal of Experimental PsychologyAnimal Behavior Processes, 32(3), 201-214. doi:10.1037/0097-7403.32.3.201
Pearce, J. M., Ward-Robinson, J., Good, M., Fussell, C., \& Aydin, A. (2001). Influence of a beacon on spatial learning based on the shape of the test environment. Journal of Experimental PsychologyAnimal Behavior Processes, 27(4), 329-344. doi:10.1037//0097-7403.27.4.329

Poucet, B. (1993). Spatial cognitive maps in animalsNew hypotheses on their structure and neural mechanisms. Psychological Review, 100(2), 163-182. doi:10.1037/0033-295X.100.2.163

Poulter, S., Hartley, T., \& Lever, C. (2018). The neurobiology of mammalian navigation. Curr Biol, 28(17), R1023-R1042. doi:10.1016/j.cub.2018.05.050

Prados, J. (2011). Blocking and overshadowing in human geometry learning. Journal of Experimental Psychology-Animal Behavior Processes, 37(1), 121-126. doi:10.1037/a0020715

Prados, J., Alvarez, B., \& Reynolds, G. (2011). Spatial integration in human geometry learning. Behavioral Brain Research, 224(2), 297-304. doi:10.1016/j.bbr.2011.06.006

Prados, J., Redhead, E. S., \& Pearce, J. M. (1999). Active preexposure enhances attention to the landmarks surrounding a Morris swimming pool. Journal of Experimental PsychologyAnimal Behavior Processes, 25(4), 451-460. doi:10.1037/0097-7403.25.4.451

Pritchard, D. J., \& Healy, S. D. (2017). Homing \& navigation. In J. Call, G. M. Burghardt, I. M. Pepperberg, C. T. Snowdon, \& T. Zentall (Eds.), APA handbook of comparative psychology (pp. 485-508). Washington, DC: American Psychiatric Association.

Redhead, E. S., \& Hamilton, D. A. (2009). Evidence of blocking with geometric cues in a virtual watermaze. Learning and Motivation, 40(1), 15-34. doi:10.1016/J.Lmot.2008.06.002

Rescorla, R. A. (1988). Pavlovian conditioning-Its not what you think it is. American Psychologist, 43(3), 151-160. doi:10.1037/0003-066x.43.3.151 
Rescorla, R. A., \& Cunningham, C. L. (1978).

Within-compound flavor associations. Journal of Experimental PsychologyAnimal Behavior Processes, 4(3), 267-275. doi:10.1037//0097-7403.4.3.267

Restle, F. (1957). Discrimination of cues in mazes - A resolution of the place-vs-response question. Psychological Review, 64(4), 217-228. doi:10.1037/H0040678

Rizley, R. C., \& Rescorla, R. A. (1972). Associations in second-order conditioning and sensory preconditioning. Journal of Comparative and Physiological Psychology, 81, 1-11. doi:10.1037/H0033333

Roberts, A. D. L., \& Pearce, J. M. (1998). Control of spatial behavior by an unstable landmark. Journal of Experimental PsychologyAnimal Behavior Processes, 24, 172-184. doi:10.1037//0097-7403.24.2.172

Rodrigo, T., Chamizo, V. D., McLaren, I. P. L., \& Mackintosh, N. J. (1994). Effects of preexposure to the same or different pattern of extra-maze cues on subsequent extra-maze discrimination. Quarterly Journal of Experimental Psychology Section BComparative and Physiological Psychology, 47, 15-26.

Rodrigo, T., Chamizo, V. D., McLaren, I. P. L., \& Mackintosh, N. J. (1997). Blocking in the spatial domain. Journal of Experimental PsychologyAnimal Behavior Processes, 23(1), 110-118. doi:10.1037/0097-7403.23.1.110

Rodríguez, C. A., Chamizo, V. D., \& Mackintosh, N. J. (2011). Overshadowing and blocking between landmark learning and shape learning: The importance of sex differences. Learning \& Behavior, 39(4), 324-335. doi:10.3758/S13420-011-0027-5

Rodríguez, C. A., Torres, A., Mackintosh, N. J., \& Chamizo, V. D. (2010). Sex differences in the strategies used by rats to solve a navigation task. Journal of Experimental PsychologyAnimal Behavior Processes, 36, 395-401. doi:10.1037/a0017297
Sage, J. R., \& Knowlton, B. J. (2000). Effects of US devaluation on win-stay and win-shift radial maze performance in rats. Behavioral Neuroscience, 114(2), 295-306. doi:10.1037//0735-7044.114.2.295

Sanchez-Moreno, J., Rodrigo, T., Chamizo, V. D., \& Mackintosh, N. J. (1999). Overshadowing in the spatial domain. Animal Learning \& Behavior, 27(4), 391-398. doi:10.3758/Bf03209976

Sanderson, D. J., \& Bannerman, D. M. (2012). The role of habituation in hippocampusdependent spatial working memory tasks: Evidence from GluA1 AMPA receptor subunit knockout mice. Hippocampus, 22(5), 981-994. doi:10.1002/Hipo.20896

Sansa, J., \& Prados, J. (2003). Ensombrecimiento entre puntos de referencia en una tarea de navegación [Overshadowing between landmarks in a navigation task]. Psicologica, 24, 17-29.

Sawa, K., Leising, K. J., \& Blaisdell, A. P. (2005). Sensory preconditioning in spatial learning using a touch screen task in pigeons. Journal of Experimental PsychologyAnimal Behavioral Processes, 31(3), 368-375. doi:10.1037/0097-7403.31.3.368

Shettleworth, S. J. (2010). Cognition, evolution, and behavior (2nd ed.). Oxford, England: Oxford University Press.

Shettleworth, S. J., \& Sutton, J. E. (2005). Multiple systems for spatial learning: Dead reckoning and beacon homing in rats. Journal of Experimental Psychology-Animal Behavior Processes, 31(2), 125-141. doi:10.1037/0097-7403.31.2.125

Small, W. S. (1901). Experimental study of the mental processes in the rat II. American Journal of Psychology, 12, 206-239. doi:10.2307/1412534

Sotelo, M. I., Alcalá, J. A., Bingman, V. P., \& Muzio, R. N. (2019). On the transfer of spatial learning between geometrically different shaped environments in the terrestrial toad, Rhinella arenarum. Animal Cognition, 23, 55-70. doi:10.1007/s10071-019-01315-9 
Sotelo, M. I., Nardi, D., Payne, K. B., Coppola, V. J., Muzio, R. N., \& Bingman, V. P. (2019). local geometric properties do not support reorientation in hippocampus-engaged homing pigeons. Behavioral Neuroscience, 133(2), 255-264. doi:10.1037/bne0000298

Spetch, M. L., Cheng, K., \& MacDonald, S. E. (1996). Learning the configuration of a landmark array: I. Touch-screen studies with pigeons and humans. Journal of Comparative Psychology, 110, 55-68. doi:10.1037/0735-7036.110.1.55

Stürzl, W., Cheung, A., Cheng, K., \& Zeil, J. (2008). The information content of panoramic images I: The rotational errors and the similarity of views in rectangular experimental arenas. Journal of Experimental Psychology-Animal Behavior Processes, 34(1), 1-14. doi:10.1037/0097-7403.34.1.1

Sutherland, R. J., Chew, G. L., Baker, J. C., \& Linggard, R. C. (1987). Some limitations on the use of distal cues in place navigation by rats. Psychobiology, 15(1), 48-57.

Taube, J. S., Muller, R. U., \& Ranck, J. B. (1990). Headdirection cells recorded from the postsubiculum in freely moving rats. I. Description and quantitativeanalysis. Journal of Neuroscience, 10(2), 420-435. doi:10.1523/JNEUROSCI.10-02-00420.1990

Tinklepaugh, O. L. (1928). An experimental study of representative factors in monkeys. Journal of Comparative Psychology, 8(3), 197-236. doi:10.1037/h0075798

Tolman, E. C. (1948). Cognitive maps in rats and men. Psychological Review, 55(4), 189-208. doi:10.1037/H0061626

Tolman, E. C., \& Honzik, C. H. (1930). Introduction and removal of reward and maze performance in rats. University of California Publications in Psychology, 4, 257-275.

Tolman, E. C., Ritchie, B. F., \& Kalish, D. (1946). Studies in spatial learning: Place learning versus response learning. Journal of Experimental Psychology, 36(3), 221-229. doi:10.1037/h0060262
Trobalon, J. B., Chamizo, V. D., \& Mackintosh, N. J. (1992). Role of context in perceptual-learning in maze discriminations. Quarterly Journal of Experimental Psychology Section B-Comparative and Physiological Psychology, 44B(1), 57-73.

Trobalon, J. B., Miguelez, D., McLaren, I. P. L., \& Mackintosh, N. J. (2003). Intradimensional and extradimensional shifts in spatial learning. Journal of Experimental PsychologyAnimal Behavior Processes, 29(2), 143-152. doi:10.1037/0097-7403.29.2.143

Trobalon, J. B., Sansa, J., Chamizo, V. D., \& Mackintosh, N. J. (1991). Perceptual-learning in maze discriminations. Quarterly Journal of Experimental Psychology Section B-Comparative and Physiological Psychology, 43(4), 389-402. doi:10.1080/14640749108401276

Wall, P. L., Botly, L. C. P., Black, C. K., \& Shettleworth, S. J. (2004). The geometric module in the rat: Independence of shape and feature learning in a food finding task. Learning \& Behavior, 32(3), 289-298. doi:10.3758/BF03196028

Watson, J. B. (1907). Kinaesthetic and organic sensations: Their role in the reactions of the white rat to the maze. Psychological Monographs, 8(2), 1-100. doi:10.1037/h0093040

Wehner, R., Hoinville, T., Cruse, H., \& Cheng, K. (2016). Steering intermediate courses: desert ants combine information from various navigational routines. Journal of Comparative Physiology A-Neuroethology Sensory Neural and Behavioral Physiology, 202(7), 459-472. doi:10.1007/s00359-016-1094-z

Williams, C. L., Barnett, A. M., \& Meck, W. H. (1990). Organizational effects of early gonadal secretions on sexual-differentiation in spatial memory. Behavioral Neuroscience, 104(1), 84-97. doi:10.1037/0735-7044.104.1.84

Williams, C. L., \& Meck, W. H. (1991). The organizational effects of gonadal-steroids on sexually dimorphic spatial ability. Psychoneuroendocrinology, 16(1-3), 155-176. doi:10.1016/0306-4530(91)90076-6 
Wilson, P. N., \& Alexander, T. (2008). Blocking of spatial learning between enclosure geometry and a local landmark. Journal of Experimental Psychology - Learning Memory and Cognition, 34(6), 1369-1376. doi:10.1037/A0013011

Yin, H. H., \& Knowlton, B. J. (2002). Reinforcer devaluation abolishes conditioned cue preference: Evidence for stimulus-stimulus associations. Behavioral Neuroscience, 116(1), 174-177. doi:10.1037//0735-7044.116.1.174

Yin, H. H., \& Knowlton, B. J. (2004). Contributions of striatal subregions to place and response learning. Learning \& Memory, 11(4), 459-463. doi:10.1101/Lm.81004 